\title{
INCREASE OF CROP YIELDS ON SEED TREATMENT BY ENVIRONMENTALLY SAFE COMPLEXONES IN SOLUTIONS
}

\author{
V.M. Nikolskiy ${ }^{1}$, L.N. Tolkacheva ${ }^{1}$, Ya.M. Khalyapina ${ }^{2}$, T.I. Smirnova ${ }^{3}$, A.A. Yakovlev ${ }^{1}$ \\ ${ }^{1}$ Tver State University, Russia, 170100, Tver, Zhelyabov str., 33 \\ ${ }^{2}$ Tver State Medical Academy, Russia, 170100, Tver, Sovetskaya str., 4 \\ ${ }^{3}$ Tver State Agricultural Academy, Russia, 170904, Tver, satl. Sakharovo, Vasilevskogo str., 7 \\ p000797@tversu.ru'; janina13@rambler.ru²
}

\begin{abstract}
In the laboratory and plot experiments the effect of ethylenediaminedisuccinic acid (EDDS) and iminodisuccinic acid (IDS) on chlorophyll content in wheat germ leaves and adult plants was investigated. It was estimated that both complexons increased chlorophyll content in leaves and crop yield.
\end{abstract}

Keywords: chlorophyll $a$, complexones, ethylenediaminedisuccinic acid, iminodisuccinic acid.

Intensive chemicalization of agriculture in all developed countries leads (apart from the increase in agricultural production) to deterioration of its quality and slow but sure pollution of the environment [1].

Therefore methods of intensification of crop-producing power which do not induce ecological disturbance of agricultural lands and adjacent regions are of utmost interest.

One of the methods is pretreatment of seeds with substances showing biological activity at minimal application dose. Some of these preparations are biometal complexonates. Their effectiveness and the level of ecological safety depend on the nature of ligands to a large extend.

For this reason preparation and investigation of new complexonates of microelements as well as investigation of biological activity of ligands in their composition are of current interest. Such widely-applied complexonates as ethylenediaminoacid (EDTA) and nitrilotriacetic acid (NTA) and their effect on the metabolism in plants are relatively well-studied $[2,3]$ whereas complexonates - succinic acid derivatives have been investigated to a considerably lesser degree [4].

As the whole complex of vital manifestations of a green plant is closely connected with the process of photosynthesis and photosynthesis in its turn- with the level of photosynthetic pigment content, it is possible to estimate the nature of the effect of external and chemical agents on the basis of chlorophyll $a$ content alteration.

In the context of investigation of complexonates succinic acid derivatives biological activity, laboratory and plot experiments were made to find out the capacity of these compounds to be absorbed and ingested by a plant body with further determination of chlorophyll content in plants and their yield level.

\section{Methods}

Seeds of winter wheat "Inna" were used for the experiment. Weighed portions of the seeds $(10,00 \pm 0,01 \mathrm{gr})$ were soaked in solutions of EDDS and IDS in concentration $1,5 \cdot 10^{-3}$ mole/l, volume $-100 \mathrm{ml}$.

Complexon solutions synthesized by the authors of the article were alkalinized with strengthened solution of $\mathrm{NaOH}$ to $\mathrm{pH}=5,6$ (pH-meter "pH-56M"). The control group included the seeds soaked in the same volume of distilled water.

In 24 hours the seeds were washed out with small portions of distilled water. The washings were added to the corresponding solutions left after soaking and the remaining content of complexons was investigated with the help of titrimetric analysis using solution of $\mathrm{Cu}\left(\mathrm{NO}_{3}\right)_{2}$ as titrant $0,002 \mathrm{M}$ and murexide indicator at $\mathrm{pH}=9,2$ (ammonium buffer).

The absorbing capacity of both complexons was determined with the help of conventional method [5].

Imbibed washed seeds -50 pieces in each experimental sample were spread on wetted absorbent paper on Petri dishes and sprouted at daylight at $\mathrm{t}^{\mathrm{o}}=22 \pm 1 \mathrm{C}^{\mathrm{o}}$ for 10 days. In 10 days leaf samples were taken to determine chlorophyll content. Pigments were estimated in acetone with the help of spectrophotometric method (photometer KFK3-01 «30M3»). Statistical analysis of the results was made with standard methods [6].

In the second part of the experiment complexons succinic acid derivatives sorption by sprout root system was investigated.

For this purpose the root system of 5 three days' germs was dipped into solutions of EDDS and IDS in concentration $1,5 \cdot 10^{-3} \mathrm{~mole} / 1$, volume - $100 \mathrm{ml}$ and distilled water, volume $-100 \mathrm{ml}$ (control group).

In 24 hours the germs were taken out of the solutions and the remaining content of the complexons in the sprouting solutions was estimated similar to the first part of the experiment.

At the same time the root system mass of the germs was determined and complexon sorption by the germ root 
system estimated. To determine the effect of complexons succinic acid derivatives (absorbed by the root system) on photosynthetic pigments' content level three days' wheat germs were left to grow in solutions of EDDS and IDS. Later using the same methods [6] photosynthetic pigments' content in the germ leaves was determined.

Both parts of the experiment were reproduced 5 times.

For making plot experiment the seeds of winter wheat were soaked in EDDS and IDS in concentration $1,5 \cdot 10^{-3}$ mole/l and in distilled water (control group). In 24 hours the wheat germs were sown in the plot $-1 \mathrm{~m}^{2} 4$ times for each part of the experiment. At the stage of forming a stem the leaves were examined for chlorophyll content.

\section{Results and discussions}

Complexon succinic acid derivatives capacity to be absorbed by seeds and root system of wheat germs determined experimentally is shown in Table 1.

Table 1

Complexon sorption from water solutions in concentration $1,5 \cdot 10^{-3} \mathrm{~mole} / \mathrm{l}$ at $\mathrm{pH}=5,6, \mathrm{~V}=100 \mathrm{ml}$ for 24 hours $\left(\mathrm{t}^{\mathrm{o}}=22 \pm \mathbf{1}^{\circ} \mathrm{C}\right)$

\begin{tabular}{|c|c|c|c|}
\hline № & Sorbent & Sorbate & Sorption micromole/gr \\
\hline 1 & Seeds & IDS & $6,8 \pm 0,6$ \\
\hline 2 & Seeds & EDDS & $7,1 \pm 0,5$ \\
\hline 3 & Root system & IDS & $9,8 \pm 0,4$ \\
\hline 4 & Root system & EDDS & $8,8 \pm 0,4$ \\
\hline
\end{tabular}

As it is shown in the table both ligands are absorbed by the seeds almost equally.

Microquantities of complexons absorbed by the wheat germs cause a small increase in the total content of green pigments mainly due to chlorophyll $a$.

The suggestion that complexon sorption is brought into the chain of germ metabolic reactions is confirmed by the data of the second part of the experiment.

As IDS sorption by germ roots is better in comparison to EDDS sorption chlorophyll content in leaves increases to a greater degree. (Table 2).

Table 2

Chlorophyll content in the leaves of wheat germs (per 100 gr of green weight) using different methods of treatment with complexon solutions in concentration $1,5 \cdot 10^{-3} \mathrm{~mole} / \mathrm{l}$ and $\mathrm{pH}=\mathbf{5 , 6}$

\begin{tabular}{|c|c|c|c|c|c|c|c|c|}
\hline \multirow{3}{*}{ № } & \multirow{3}{*}{$\begin{array}{l}\text { The object of } \\
\text { influence }\end{array}$} & \multirow{3}{*}{$\begin{array}{c}\text { Option } \\
\text { experience }\end{array}$} & \multicolumn{6}{|c|}{ Chlorophyll } \\
\hline & & & \multicolumn{2}{|c|}{$\mathbf{a}$} & \multicolumn{2}{|c|}{$\mathbf{b}$} & \multicolumn{2}{|c|}{$\mathbf{a}+\mathbf{b}$} \\
\hline & & & $\mathbf{m}$ & $\begin{array}{c}\% \\
\text { of control }\end{array}$ & $\mathbf{m}$ & $\begin{array}{c}\% \\
\text { of control }\end{array}$ & m & $\begin{array}{c}\% \\
\text { of control }\end{array}$ \\
\hline 1 & Seeds & $\begin{array}{l}\mathrm{H}_{2} \mathrm{O} \text { dest } \\
\text { (control) }\end{array}$ & $69,4 \pm 0,3$ & - & $25,1 \pm \pm 0,3$ & - & $94,4 \pm \pm 0,3$ & - \\
\hline 2 & Seeds & IDS & $72,4 \pm 0,4$ & 104 & $24,6 \pm \pm 0,3$ & 98 & $96,9 \pm \pm 0,4$ & 103 \\
\hline 3 & Seeds & EDDS & $76,6 \pm 1,0$ & 110 & $24,0 \pm \pm 0,1$ & 96 & $100,6 \pm \pm 1,0$ & 107 \\
\hline 4 & Root system & $\begin{array}{l}\mathrm{H}_{2} \mathrm{O} \text { dest } \\
\text { (control) }\end{array}$ & $93,4 \pm 0,9$ & - & $20,3 \pm \pm 0,7$ & - & $113,7 \pm \pm 0,9$ & - \\
\hline 5 & Root system & IDS & $126,8 \pm \pm 0,4$ & 136 & $18,9 \pm \pm 0,5$ & 93 & $145,7 \pm \pm 0,5$ & 128 \\
\hline 6 & Root system & EDDS & $116,5 \pm \pm 0,3$ & 125 & $22,8 \pm \pm 0,5$ & 112 & $139,3 \pm \pm 0,5$ & 123 \\
\hline
\end{tabular}

Judging by the results of quantitative analysis of pigments, complexons absorbed by the seeds or root system at the first stages of wheat plant development slightly effect on the level of chlorophyll b content but considerably increase chlorophyll a content - the main photosynthetic pigment.

Apparently in germ organisms both complexons (being aminoacids) undergo biochemical destruction forming carboxylic acids - common aminoacids and other products non-toxic for plants but capable of interacting in anabolic processes of plant development which is confirmed by an increase in the total number of green pigments in experimental plants in comparison to control group.

The results of the plot experiment are given in Table 3 . 
Table 3

Chlorophyll content in leaves and crop yield of winter wheat using different methods of seed pretreatment

\begin{tabular}{|c|c|c|c|c|c|c|}
\hline \multirow{2}{*}{ № } & \multirow{2}{*}{$\begin{array}{c}\text { Option pretreatment of } \\
\text { seeds }\end{array}$} & \multicolumn{2}{|c|}{$\begin{array}{c}\text { Chlorophyll content on 100 gr the } \\
\text { raw leaves }\end{array}$} & $\begin{array}{c}\text { Crop yield, } \\
\text { c/ha }\end{array}$ & $\begin{array}{c}\text { Increase in relation to the } \\
\text { control, c/ha }\end{array}$ \\
\cline { 2 - 5 } & & $\mathbf{a}$ & $\mathbf{b}$ & $\mathbf{a}+\mathbf{b}$ & & - \\
\hline 1 & $\mathrm{H}_{2} \mathrm{O}$ dest (control) & $60 \pm 2$ & $139 \pm 5$ & $199 \pm 5$ & 11,78 & 1,39 \\
\hline 2 & EDDS & $76 \pm 2$ & $164 \pm 6$ & $240 \pm 6$ & 13,17 & 0,64 \\
\hline 3 & IDS & $66 \pm 3$ & $152 \pm 2$ & $218 \pm 3$ & 12,42 & \\
\hline
\end{tabular}

Seed pretreatment produced greater effect on adult plants than germs.

The investigation proved EDDS and IDS sorption capacity from the water environment in the form of atactic anions by plumping seeds and wheat germ root system as well as their action stimulating the formation of photosynthetic pigments in the leaves resulting in the increase of crop yield.

Therefore we came to the conclusion that EDDS and IDS show biological activity not only as parts of metal complexes $[8,9]$ but in their free state as well.

\section{References:}

[1]. A.A. Shakhov. Photo-energetics plant and harvest. - M: Science. 1993. P. 6.

[2]. N.M. Dyatlova, V.Ya. Temkina, K.I. Popov. Complexones and metal complexonates. - M.: Chemistry. 1988. pp. $474-491$.

[3]. L.I. Martynenko, N.P. Kuzmina. Chemistry of complexones and their use. - Kalinin: KSU. 1986. pp. 15 - 17.

[4]. I.P. Gorelov, V.M. Nikolskiy, A.G. Muhometzyanov, N.N. Abramovskaya, S.S. Ryasensky, O.J. Myasnikova, A.V. Pugaev, L.A. Mayorova // J. Chemistry in agriculture 1987. V. 25. № 1. pp. 48 - 49.

[5]. I.P. Gorelov, A.P. Samsonov, V.M. Nikolskiy, V.A. Babich, Yu.E. Svetogorov, T.I. Smirnova, E.D. Malakchaev, A.I. Kapustnikov, Yu.M. Kozlov // Journal of General Chemistry. 1979. V. 49. № 3. pp. 659 - 663.

[6]. L.P. Sadovnichnaya, V.G. Huhryansky, A.Ya. Tsyganenko. Biophysical chemistry. - Kiev. 1986. P. 174.

[7]. V.F. Gavrilenko, T.V. Zhigalova. Large practicum on photosynthesis. - M. 2003. pp. 46 - 54, pp. 222 - 231.

[8]. Z.I. Usanova, T.I. Smirnova, N.N. Ivanyutina, D.S. Muravev, D.V. Safronov // Bulletin TSU. Ser.: Biology and Ecology. - 2008. № 10. pp. 98 - 101.

[9]. T. Vamerali, M. Bandiera, G. Mosca. Field corps for phitoremediaton of metal - contaminated // Environmetal Chemistry Letters - 2010. V. 8. № 1. pp. $1-17$. 